\title{
Changing Approaches to Mental Healthcare in the Caribbean Conferences on Mental Health, 1957-1969 ${ }^{1}$
}

\author{
Deborah Toner ${ }^{2}$, Clare Anderson ${ }^{3}$ and Shammane Joseph Jackson ${ }^{4}$
}

\begin{abstract}
This paper examines discussions among physicians, psychologists, public health officials, religious leaders and others who participated in the Caribbean Conferences on Mental Health between 1957 and 1969. Their discussions demonstrate major changes in the understanding of causes, definitions and appropriate treatments of mental health conditions, compared to the late nineteenth century, which saw a wave of major reforms to the management of mental illness in public asylums. Although major shifts in professional understandings of mental health were evident in the mid-twentieth century, the Caribbean Conferences on Mental Health reveal that the problems hindering the implementation of these new approaches were largely similar to those that Guyana and other Caribbean countries continue to face today.
\end{abstract}

Keywords: Guyana, Caribbean, Mental Health, Preventative Care, Incarceration.

\section{Introduction}

Major efforts to understand and address mental health issues have been ongoing across CARICOM countries since 2010 and formed an important part of the National Health Strategy launched in Guyana in 2015. These include urgent campaigns to tackle crises, such as the high self-harm and suicide rates in Guyana, as well as greater investment and training programmes to facilitate increased differentiation in the treatment of people with diagnosed conditions and broader mental health support programmes for the public at large. But these efforts have faced major obstacles, including severe shortages of personnel and resources; continuing social stigmatisation of mental health conditions; and difficulty engaging with remote communities (Halliwell 2019; Stabroek News 2015). These difficulties, and the consequent disjuncture between an ethos of supporting good mental health for all and the reality of available services, have been long-standing challenges. They dominated discussions during the first crossCaribbean project to improve mental health at a population level during the late 1950s and 1960s, under the auspices of the Caribbean Federation for Mental Health.

This paper examines discussions among physicians, psychologists, public health officials, religious leaders and others who participated in the Caribbean Conferences on Mental Health between 1957 and 1969. Their discussions demonstrate major changes in the understanding of causes, definitions and appropriate treatments of mental health conditions, compared to the late nineteenth century, when Robert Grieve, the Medical Superintendent of

\footnotetext{
1 This paper is based on research conducted for the ESRC-funded project Mental Health, Neurological and Substance Abuse (MNS) Disorders in Guyana's Jails: 1825 to the present day (award no. ES/S000569/1). This project is a collaboration between the University of Guyana and the University of Leicester, in partnership with the Guyana Prison Service. The project brings into dialogue researchers in History, Criminology, Sociology and Literature. It takes both a multi-disciplinary and interdisciplinary approach to key questions about the form, function, and experience of incarceration, encompassing inmates and the people who work with them. It encompasses both the British colonial period, and the era since Guyana's independence in 1966.

${ }^{2}$ Associate Professor of History, School of History, Politics and International Relations, University of Leicester, Leicester, UK. Email: dt151@le.ac.uk. ORCID: 0000-0003-3052-8642.

${ }^{3}$ Professor of History, School of History, Politics and International Relations, University of Leicester, Leicester, UK. Email: ca26@le.ac.uk. ORCID: 0000-0003-0679-887X.

${ }^{4}$ Lecturer, Department of History and Caribbean Studies, University of Guyana, Georgetown, Guyana. Email: shamannejoseph@yahoo.com.
} 
the Public Lunatic Asylum in British Guiana (1875-1886), led a wave of major reforms to the management of mental illness in public asylums. Although major shifts in professional understandings of mental health were evident in the mid-twentieth century, the Caribbean Conferences on Mental Health reveal that the problems hindering the implementation of these new approaches were largely similar to those that Guyana and other Caribbean countries continue to face today.

\section{Towards Outpatient, Community-Based and Preventative Mental Health Programmes}

The Caribbean Federation for Mental Health (CFMH) was established in 1959, two years after the foundational Caribbean Conference on Mental Health in Aruba. The conference took inspiration from the World Health Organization (WHO)'s vision for the promotion of 'complete physical, mental and social well being' (CCMH 1957, 13). During the formal opening of the 1957 conference, Dr C. van den Berg, from the Department of Social Affairs and Public Health at The Hague, cited this WHO view to inform the ideal evolution of mental health treatment towards its fifth, and final, stage of historical development: prevention. The previous four stages in the treatment of mental illness he identified were: confinement in prisons; more humane forms of confinement; the use of mental hospitals; and systems of outpatient care (CCMH 1957, 15-16). Papers and discussions in this and subsequent conferences, however, show that the progression that van den Berg outlined was by no means a linear process; the mental health landscape across the Caribbean in the 1950s and 1960s combined elements of all five "stages".

Participants in the mental health conferences during this period certainly embraced the ethos that systems of outpatient or community care would improve recovery rates of persons with diagnosed mental health conditions. The main goal of the 1959 conference in the Virgin Islands, for example, was to explore the implementation of community-based and social care, underpinned by a recognition that resource-intensive means, such as building new hospitals or specialist institutions, was beyond the reach of most government budgets (CCHM 1961, 3-4). Delegates from the British Guiana Mental Health Association, formed in 1963, reported to the 1965 Jamaica conference that one of their immediate objectives was to establish a 'family and children's counselling centre' in Georgetown (Dummett 1965, 4). The same conference concluded with a series of recommendations to governments designed to provide holistic medical and social care to mental health patients by establishing psychiatric units within general hospitals, as opposed to expanding psychiatric hospitals, and by developing new outpatient and community-run services (CCMH 1965c, 8).

Some countries were able to implement these recommendations subsequently, albeit on a small scale. In 1967, for instance, Joan DeSouza and Michael H. Beaubrun of the University of the West Indies (Mona) presented a paper outlining improved recovery and reintegration into society of patients who had been treated with a short programme of medical and therapeutic interventions, in a small psychiatric unit within the Mona General Hospital, before being released to outpatient care. They attributed these patients' better prognoses, lower recurrence rates, and better employment rates compared to patients admitted to mental institutions to their shorter, more intensive treatment. They argued that this helped them to avoid developing chronic problems and created a 'better community image' of them upon release (DeSouza and Beaubrun 1967, 7-8). By this time, the Mental Health Federation of Jamaica had also started a Citizen's Information Centre to direct people to available mental health facilities, in partnership with a Roman Catholic Family Counselling Centre. They also encouraged service clubs, such as the Lions' Clubs and Rotary of Jamaica, to set up mental 
health committees, rehabilitation projects and educational talks for GPs, nurses, police officers and prison officers (Royes and Francis 1967, 31-2).

Conference participants further demonstrated strong support for preventative measures intended to reduce the prevalence of mental health issues at the population level, by consistently identifying broad social problems as the main causes of mental ill-health. Rapid social and economic changes brought by expanding tourism and extractive industries gave rise to increased migration and mobility for work, exacerbating longer-standing regional issues of social dislocation, complex cultural intermixture, family instability, and inequalities in education, employment, housing and transport. These were considered either serious risk factors for, or direct causes of anxiety and depression, delinquency, anti-social behaviour and alcohol abuse (CCMH 1957, 8-9, 12; Redl 1961, 83-4; CCMH 1961, 101, 130-4; Schaffner 1965, 12-14). Participants recurrently argued that historical processes of colonialism, slavery and indenture had not only fed into these socio-economic inequalities and racial divisions, but also left psychological legacies directly in the form of widespread feelings of dependency, powerlessness and inferiority (CCMH 1957, 48; Beaubrun 1965a, 34; Henriques 1969, 14-23; Beaubrun 1969, 87, 95; Knight 1969, 101). These issues were examined with greater depth as Caribbean speakers took more prominence on the conference programmes. In his 1963 keynote address, Michael Beaubrun, the Trinidadian President of the CFMH, highlighted that most of the speakers in the first two conferences had been from outside the Caribbean. In the immediate aftermath of Jamaica's and Trinidad and Tobago's independence, Beaubrun welcomed the increased prominence and sharing of Caribbean expertise on mental health issues specific to the region and its colonial history. In particular, he compared the prevalence of depression and alcoholism amongst East Indian patients and schizophrenia and mania amongst black patients in British Guiana and Trinidad, in relation to differences in typical family structure connected to different historical experiences of slavery and indentured labour in the plantation economy (1965a, 27-34).

For the British Guiana Mental Health Association broad social causes of mental ill health required preventative measures for society as a whole. In its report to the 1965 conference, the association outlined plans, involving religious leaders, probation officers, social workers, schools, medical doctors and a psychiatrist, to raise public awareness of mental health issues and thereby promote de-stigmatisation and early intervention (Dummett 1965, 16). The keynote address at the 1967 conference in Barbados, and the conference's central theme, was 'Society and its Responsibility for Mental Health', which emphasised the importance of understanding mental health as a public health issue at population level and identified broad social patterns of poverty, migration, unemployment and inequality as the key sources of mental health problems (Yolles 1967, 4). The 1969 conference examining group tensions across racial and generational lines likewise stressed the key strategy should be the 'positive conservation and protection of the population's mental health' (Griffin 1969, 4). Applying this preventative approach to the mental health problems linked to the psychological legacies of colonialism, Michael Beaubrun recommended the adoption of policies promoting greater economic equality, incorporating the historical and cultural achievements of different ethnic groups in schools' history curricula, resisting segregation in schools and celebrating unifying symbols and cultural festivals such as Carnival (1969: 87, 95. See also Knight 1969, 101-3).

Although many professionals involved in these conferences had embraced the ethos and ambition of improving mental health for everyone and supporting persons with specific mental health conditions through a greater range outpatient and community services, it is clear 
that confinement and institutionalisation still played a significant role in the management of mental health in the Caribbean. Conference participants often suggested that the lack of outpatient and community facilities meant that there was no alternative to placing patients in mental institutions or even prison, and that the lack of trained personnel and resources meant that mental hospitals sometimes operated under prison-like conditions. They also pointed to public attitudes towards mental health patients and institutions that shaped both the practice of institutionalisation or incarceration and poor prospects for patients' successful reintegration into society upon their release.

\section{Confinement, Institutionalisation and Stigmatisation of Mental Health Patients}

Dr C. van den Berg's opening address outlining five stages in the development of mental health treatments admitted that most countries had not yet achieved the fifth "preventative" stage, but implied that the "earlier" stages of treatment, especially different forms of confinement, were increasingly consigned to the past. Leonard Smith (2014) has shown that the late nineteenth century saw a concerted effort to change asylums in the British Caribbean from custodial to rehabilitative institutions. As Medical Superintendent of the British Guiana Lunatic Asylum, which opened near New Amsterdam in 1866, Robert Grieve instituted a regime of moral management between 1875 and 1885, which became influential across the Caribbean. This included removing prison-like features from asylum buildings, such as iron window bars, and instituting a policy of non-restraint to avoid locking patients in cells for long periods or using devices like iron handcuffs, leather straps and straitjackets. Buildings were refurbished to make them more pleasant spaces and patients were engaged in programmes of work, including agriculture, carpentry, tailoring, painting, shoemaking, printing, cleaning and cooking, as well as forms of entertainment, such as music, dance and sports. These measures were underpinned by the idea that a therapeutic, rather than custodial, environment was necessary for recovery from mental health conditions and that structured programmes of work could help to restore order to disordered minds. Although this approach was not altogether abandoned after Grieve's departure, overcrowding and poor living conditions severely curtailed its operation (Smith 2014, 97-102. See also Gampat 2015, 588-94; Gramaglia 2013).

Discussions at the mental health conferences in the 1950s and 1960s suggest that custodial approaches were still used in the Caribbean, despite general agreement amongst participants that they should be retired. This seemed to be particularly the case for people suffering from alcohol abuse. In the 1957 conference, in which alcohol addiction was singled out as the biggest mental health problem in Aruba, the Chairman of the Aruba Society Against Alcoholism, formed in 1955, lamented the lack of rehabilitation facilities which meant that 'the only alternative to freeing the offender is prison' (CCMH 1957, 65). A report on the establishment of an Alcoholic Treatment Centre in 1961 at St Ann's Hospital, Trinidad, suggested that it sometimes admitted patients after imprisonment. The report outlined a threestage treatment programme combining, at times, incarceration, in-patient care in the hospital, and outpatient or community care organised by Alcoholics Anonymous. The first stage was recognising the problem, either voluntarily, under compulsion by a family member or employer, or as a requirement following an alcohol-related crime (Pinto 1965, 172).

Initiatives to diminish the custodial aspects of mental hospitals and psychiatric wards within general hospitals, or to expand outpatient and community care services, suggest that mental health patients could still be subject to prison-like conditions. Moreover, they suggest that aspects of the criminal justice system and broader public attitudes stigmatising mental health conditions were barriers to improving this situation. The 1965 seminar in Jamaica recommended an urgent review of laws, legal procedures and court-ordered psychiatric 
admissions to assess two interlinked problems: the use of psychiatric wards as substitute prisons in cases of prison overcrowding, and a lacunae of appropriate care for incarcerated mental health patients (CCMH 1965c, 11). The Mental Health Federation of Jamaica reported in 1967 on the impact of their educational work with medical staff, police and prison officers, and the general public on challenging 'erroneous beliefs ... that the mentally ill... need to be "put away" with finality'. It was, they said, 'becoming increasingly natural' for people with mental health conditions to be taken directly to mental health facilities instead of to the jailhouse', but that more work was needed to remove the 'prison-like' features of hospitals and to remove 'legal charges of lunacy from the statute books' (Royes and Francis 1967, 31-2). Representatives from Barbados in 1967 likewise stressed the importance of destigmatising mental health patients through reducing reliance on facilities with locked doors and powers of detention (DeSouza and Beaubrun 1967, 8).

Efforts to replace custodial with rehabilitative features of mental hospitals and psychiatric wards within general hospitals were clearly hampered by insufficient staffing levels and a lack of mental health specialists. The central outcome of the 1963 conference in Curaçao was a plan that all individual associations could present to governments for investment in training mental health personnel, alongside cross-Caribbean training exchanges. Barbados offered places on a newly developed intensive week-long course in treating acute mental health crises; the Volunteer Professional Services Program, started in 1962, was sending small numbers of psychiatrists, psychologists and social workers to different parts of Caribbean to train others; and the University of the West Indies (Mona) was in the process of establishing a new Department of Psychiatry within the medical school in Jamaica, which aimed to coordinate such exchanges in future (Schaffner, 1965, pp. 13-15). Still, in 1965, Michael Beaubrun reported that there were only 17 full-time psychiatric doctors in the whole British Caribbean, serving a population of roughly 4 million, and highlighted severe shortages of mental health specialists in social work, nursing, teaching and counselling (1965b, 2-3). Poor transport links to some parts of the region also meant the training exchange program was difficult to access. The British Guiana Mental Health Association explained in 1965, for example, that plans to establish a counselling centre had been delayed because the CFMH's psychiatric social worker had been unable to travel to British Guiana (Dummett 1965, 4-5].

\section{Conclusion}

Tackling personnel shortages and limited facilities, alongside destigmatising mental health conditions, remain key challenges in addressing mental health problems in Guyana and the wider Caribbean today (Halliwell 2019). The cross-Caribbean conferences of the 1950s and 1960s reveal that professionals involved in mental healthcare wanted to increasingly adopt preventative and non-institutionalised approaches to treating mental health problems but were often frustrated in those ambitions. To conference participants' general dismay, prison-like conditions in hospitals, which Robert Grieve's programme of moral management had sought to remove from asylums in the late nineteenth century, were still in evidence, as was a public attitude that mental health patients needed to be incarcerated. They launched various initiatives to expand the range of outpatient and community-based facilities for supporting people with diagnosed mental health conditions, improving the mental health of the population at large, and educating various publics to promote de-stigmatisation. However, their preventative ethos also emphasised that social inequalities with deep historical roots contributed to mental health problems in the Caribbean, requiring structural changes to society that have proven difficult to achieve. 


\section{References}

Beaubrun, Michael H. (1965a) 'Keynote Address', in CCMH (1965a) Fourth Caribbean Conference for Mental Health, Curaçao, April 16-23 1963, Netherlands Antilles: Family Relationships. Curaçao: no publisher, pp. 27-35.

Beaubrun, Michael H. (1965b) 'Psychiatric Education for the Caribbean' in CCMH (1965b) Caribbean Seminar on Mental Health, Kingston, Jamaica, 5-11 September 1965. No place: no publisher, Section 4, pp. 1-20.

Beaubrun, Michael H. (1969) 'Community Programmes for the Resolution of Group Tensions', in CCMH (1969) Report on the Seventh Caribbean Conference for Mental Health. Group Tensions and Mental Health, held at the University of the West Indies, St. Augustine, Trinidad, 27th July to 2nd August, 1969. Port-of-Spain: Trinidad and Tobago Association for Mental Health, pp. 85-95.

DeSouza, Joan and Beaubrun, Michael H. (1967) 'An Evaluation of the UWI Programme of Community Psychiatric Care', in CCMH (1967) Resumé of Sixth Caribbean Conference for Mental Health, Barbados, July 31 to August 4 1967. No place: no publisher, pp. 6-7.

Dummett, A. (1965) 'Mental Health in British Guiana', in CCMH (1965b) Caribbean Seminar on Mental Health, Kingston, Jamaica, 5-11 September 1965. No place: no publisher, Section 12, pp. 1-6.

CCMH (1957) Constructive Mental Hygiene in the Caribbean. Proceedings of the First Caribbean Conference on Mental Health, March 14-19, 1957, Aruba, Netherlands Antilles. Assen: Koninklijke Van Gorcum \& Comp.

CCMH (1961) Children of the Caribbean: Their Mental Health Needs. Proceedings of the Second Caribbean Conference for Mental Health, April 10-16, 1959, Saint Thomas, Virgin Islands. San Juan: Department of the Treasury.

CCMH (1965a) Fourth Caribbean Conference for Mental Health, Curaçao, April 16-23 1963, Netherlands Antilles: Family Relationships. Curaçao: no publisher.

CCMH (1965b) Caribbean Seminar on Mental Health, Kingston, Jamaica, 5-11 September 1965. No place: no publisher.

CCMH (1965c) 'Final Report of the Caribbean Seminar in Mental Health', in CCMH (1965b) Caribbean Seminar on Mental Health, Kingston, Jamaica, 5-11 September 1965. No place: no publisher, section 30, pp. 1-27.

CCMH (1967) Resumé of Sixth Caribbean Conference for Mental Health, Barbados, July 31 to August 4 1967. .No place: no publisher.

CCMH (1969) Report on the Seventh Caribbean Conference for Mental Health. Group Tensions and Mental Health, held at the University of the West Indies, St. Augustine, Trinidad, 27th July to 2nd August, 1969. Port-of-Spain: Trinidad and Tobago Association for Mental Health.

Gampat, Ramesh (2015) Guyana: From Slavery to the Present. Vol. 2 Major Diseases. Bloomington: Xlibris.

Gramaglia, L. (2013) 'Migration and Mental Illness in the British West Indies 1838-1900: The Cases of Trinidad and British Guiana', in Catherine Cox and Hilary Marland, eds, Migration, Health and Ethnicity in the Modern World. Basingstoke: Palgrave, pp. 61-82. 
Griffin, J.D. (1969) 'Group Tensions and Mental Health', in CCMH (1969) Report on the Seventh Caribbean Conference for Mental Health. Group Tensions and Mental Health, held at the University of the West Indies, St. Augustine, Trinidad, 27th July to 2nd August, 1969. Portof-Spain: Trinidad and Tobago Association for Mental Health, pp. 3-13.

Halliwell, M. (2019) 'Mental Health and Suicide Prevention in Guyana', MNS Disorders in Guyana's Jails, 1825 to the Present, 16 December 2019. Available at https://mnsguyana.le.ac.uk/2019/12/16/mental-health-and-suicide-prevention-in-guyana/ (Accessed on 24 March 2020).

Henriques, Fernando (1969) 'Tensions Between Racial and Ethnic Groups', in CCMH (1969) Report on the Seventh Caribbean Conference for Mental Health. Group Tensions and Mental Health, held at the University of the West Indies, St. Augustine, Trinidad, 27th July to 2nd August, 1969. Port-of-Spain: Trinidad and Tobago Association for Mental Health, pp. 14-23.

Knight, Frank (1969) 'Self-image in the Caribbean', in CCMH (1969) Report on the Seventh Caribbean Conference for Mental Health. Group Tensions and Mental Health, held at the University of the West Indies, St. Augustine, Trinidad, 27th July to 2nd August, 1969. Port-ofSpain: Trinidad and Tobago Association for Mental Health, pp. 100-104.

Pinto, Heather (1965) 'Group Therapy among Alcoholics' in CCMH (1965a) Fourth Caribbean Conference for Mental Health, Curaçao, April 16-23 1963, Netherlands Antilles: Family Relationships. Curaçao: no publisher, pp. 169-176.

Redl, Fritz (1961) 'Thoughts on the Prevention of Delinquency', in CCMH (1961) Children of the Caribbean: Their Mental Health Needs. Proceedings of the Second Caribbean Conference for Mental Health, April 10-16, 1959, Saint Thomas, Virgin Islands. San Juan: Department of the Treasury, pp. 69-91.

Royes, Kenneth and Francis, Edna (1967) 'Stimulating Community Interest in Mental Health', in CCMH (1967) Resumé of Sixth Caribbean Conference for Mental Health, Barbados, July 31 to August 4 1967. No place: no publisher, pp. 31-32.

Schaffner, Bertram (1965) 'Aims and Results of the Curaçao Conference', in CCMH (1965a) Fourth Caribbean Conference for Mental Health, Curaçao, April 16-23 1963, Netherlands Antilles: Family Relationships. Curaçao: no publisher, pp. 11-16.

Smith, Leonard (2014) Insanity, Race and Colonialism: Managing Mental Disorder in the Post-Emancipation British Caribbean 1838-1914. London: Palgrave Macmillan.

Stabroek News (2015) 'Differentiated Care to be Offered to Mental Health Patients', Stabroek News, 13 October 2015, pp. 17-21.

Yolles, Stanley (1967) 'Society and its Responsibility for Mental Health', in CCMH (1967) Resumé of Sixth Caribbean Conference for Mental Health, Barbados, July 31 to August 41967. No place: no publisher, pp. 3-5. 